\title{
Phenylethylmalonamide in essential tremor. A double-blind controlled study
}

\author{
S CALZETTI,* LJ FINDLEY, † F PISANI,* A RICHENS $\ddagger$ \\ From the Clinical Pharmacology Unit, Institute of Neurology, ${ }^{*}$ and the MRC Hearing and Balance Unit, \\ The National Hospital, $\uparrow$ London
}

SUMMARY A randomised double-blind placebo-controlled trial of phenylethylmalonamide, the major metabolite of primidone was performed in eight patients with essential tremor. Phenylethylmalonamide was given in a daily dose of $400 \mathrm{mg}$ for one week and $800 \mathrm{mg}$ for a second week. The compound had no statistically significant effect on the amplitude of tremor assessed by an accelerometric method, tests of performance, clinical evaluation and patient self assessment. No side effects occurred. Serum levels of phenylethylmalonamide on a daily dose of $400 \mathrm{mg}$ were $11-27 \mu \mathrm{g} / \mathrm{ml}$ and on $800 \mathrm{mg}$ daily were $16-48 \cdot 5 \mu \mathrm{g} / \mathrm{ml}$.

Benign essential tremor is a common disorder of the nervous system which, in spite of its name, frequently produces significant disability. The $\beta$-adrenoceptor antagonist propranolol is considered a drug of first choice in this condition, but the clinical responsiveness to the drug is unpredictable and often not completely satisfactory. ${ }^{1}$ O'Brien, Upton and Toseland $^{2}$ reported that primidone, a well-established anticonvulsant drug, was found to be highly effective, even better than propranolol. The authors correlated the plasma levels of primidone and its major active metabolites, phenylethylmalonamide (PEMA) and phenobarbitone, with the clinical state in two patients and suggested that the efficacy of primidone was mainly mediated by PEMA, although it had not been excluded that the parent drug itself may have exerted some effect. This finding is of interest for its therapeutic implications but unfortunately the report was based on uncontrolled clinical observations and so it does not provide a reliable estimate of the effectiveness of primidone or PEMA in essential tremor. We report a randomised double-blind placebo-controlled trial of PEMA in this condition.

$\ddagger$ Present address: Department of Pharmacology, Welsh National School of Medicine, Heath Park, Cardiff CF4 4XN, Wales.

Address for reprint requests: Dr LJ Findley, MRC Hearing and Balance Unit, The National Hospital, Queen Square, London WC1N 3BG, UK.

Submitted 10 July 1981

Accepted 6 August 1981

\section{Method}

Eight male patients with moderate to severe essential tremor aged 28-69 years (mean 58) and weighing between $55-80 \mathrm{~kg}$ (mean 70) who were attending the out-patient clinic at the National Hospital, Queen Square, took part in the study. All had been symptomatic for at least 5 years and in three there was a family history of tremor involving the hands or head or both. In these patients the dominant peak frequency of tremor in the more involved hand ranged from $4 \cdot 2$ to $7 \cdot 8 \mathrm{~Hz}$ (mean 5.9). None of the patients was receiving drug treatment for tremor at the time of the trial. This study was double blind and placebo controlled. PEMA was supplied in powder form by Desitin-Werk (Hamberg) and prepared for oral administration in soft gelatin capsules. Each patient was given PEMA or matched placebo for two weeks respectively in a randomised order according to a cross-over design. The dosage of PEMA chosen was $200 \mathrm{mg}$ twice a day for the first week and $400 \mathrm{mg}$ twice a day for the second week. The maximum dosage of PEMA used was that expected to result in a steady state serum level of PEMA similar to that which would be produced by a dosage of primidone of about $1500 \mathrm{mg}$ daily. ${ }^{3}$ Patients were asked to abstain from alcohol, cigarettes and caffeinated beverages for three hours prior to each tremor assessment. They were instructed to take their last capsule two hours before tremor assessment.

Tremor was measured at the end of the first and second week of drug and placebo treatments by accelerometric recordings, and at the same time clinical evaluation, performance tests and patients self-assessment were carried out. Tremor was recorded using linear piezoresistive accelerometers (ENDEVCO 7265-10), taped to 
the dorsal surface of both hands in the second interspace about $1 \mathrm{~cm}$ proximal to the metacarpophalangeal joints with the sensitive axis orientated in the vertical plane. These devices weighed $6 \mathrm{~g}$ and had a sensitivity of 50 $\mathrm{mV} / \mathrm{g}$ ( $g=$ acceleration of gravity). Hand tremor was assessed with the patient seated, fully relaxed and looking directly ahead. The forearms were supported up to the wrist, and the hands, were unsupported and outstretched horizontally in a pronated posture during the recordings. On each occasion three separate tremor recordings of about one minute duration were obtained at five minute intervals and to minimise the possible effects of fatigue the hands were allowed to rest freely between recordings. Accelerometric signals were amplified and recorded simultaneously on paper using a Elema-Shonander Recorder, and on magnetic tape for subsequent analysis. All the tests were performed by the same investigator (SC).

Tremor analysis was performed off line using a Hewlett Packard 5420A signal analyser. On each occasion of tremor recording the program averaged 150 autospectra each derived from overlapping $10 \cdot 24 \mathrm{~s}$ samples of tremor. Fifty samples were taken from the beginning of each of the three separate recordings and approximately $45 \mathrm{~s}$ of tremor recording contributed to the analysis of each condition. The averaged spectra were displayed for
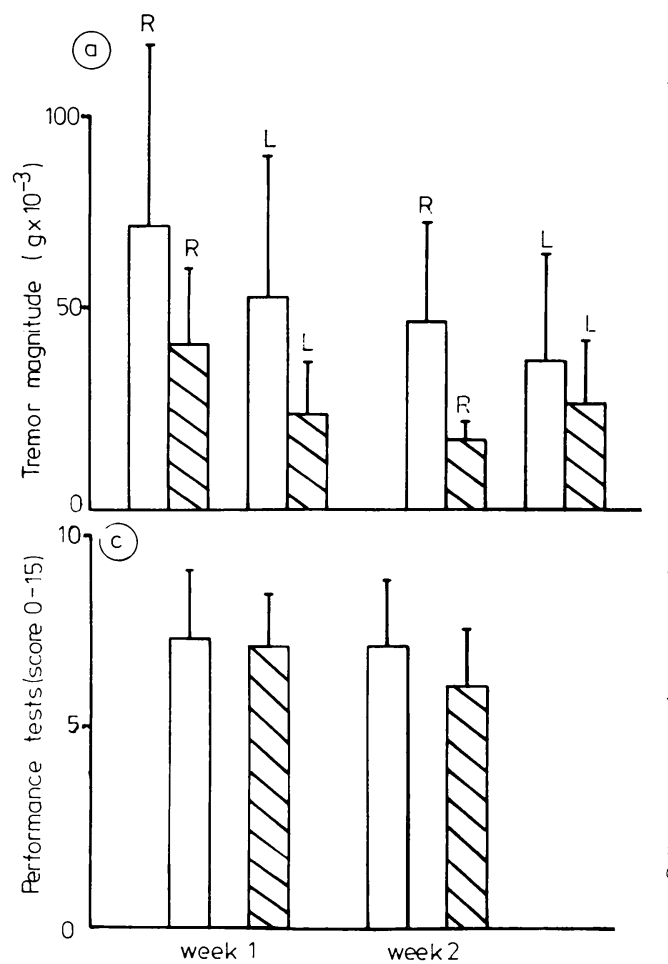

measurement and the root mean squared (rms) magnitude of the frequency components was plotted as a function of frequency. For a simple characterisation of tremor, measurements were taken of the frequency of the dominant peak and of its magnitude scaled in rms acceleration, the unit of acceleration being taken as $g\left(g=981 \mathrm{~cm} / \mathrm{s}^{2}\right)$. As it was found that in any patient the dominant tremor frequency did not vary significantly at different recording sessions, the magnitude of acceleration was proportional to the amplitude of hand displacement, that is amplitude of displacement $=\left([\right.$ acceleration $\times 981] / 4 \times \pi^{2} \times$ frequency $\left.^{2}\right) \mathrm{cm}$ rms. For statistical analysis the values of tremor magnitude obtained from either hand were used.

Clinical assessment of postural and intention tremor of the hands and performance tests (handwriting, drawing and tracing) were each quantitated on an arbitrary scale from $0-5(0=$ good, $5=$ bad $)$. The performance tests were evaluated by three different assessors and the final score for each patient was the mean of the three independent evaluations. The patient self assessment was determined on a similar arbitrary scale from 0-5 and included in the ability to perform daily living activities and family opinion about change in tremor.

Blood samples were collected at the end of each recording session. PEMA was determined in serum by gas-liquid chromatography with flame-ionisation detection. In brief

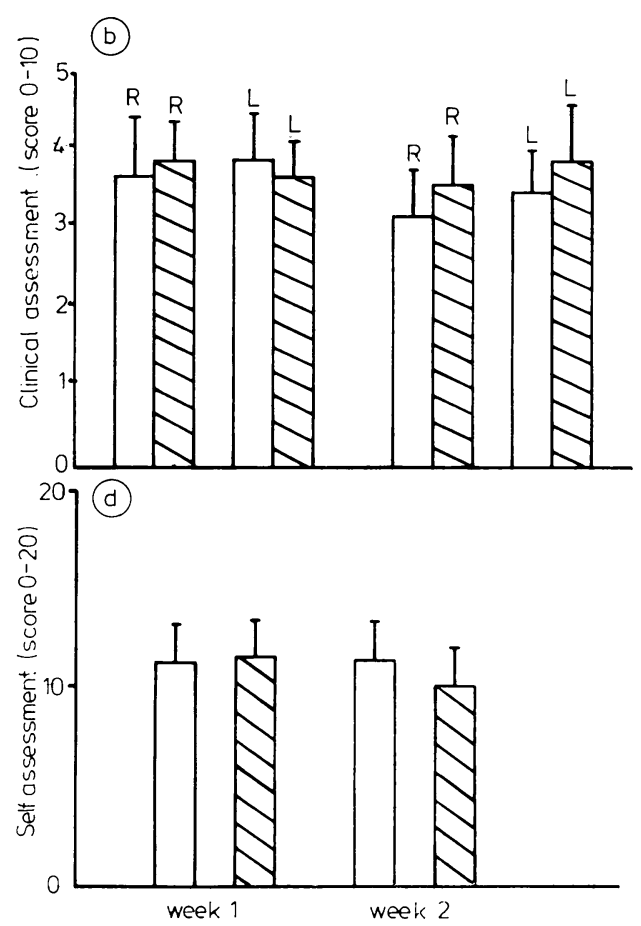

Figure Values of tremor magnitude $\left(\right.$ in $\left.\mathrm{g} \times 10^{-3}\right)(A)$, clinical assessment $($ score 0-10) $(B)$, performance tests (score 0-15) (C) and of self assessment (score 0-20) (D) during PEMA and placebo regimen in 8 patients with essential tremor. Clear bars represent mean $\pm S E M$ on PEMA and shaded bars represent mean $\pm S E M$ on placebo. $R$ is right hand, $L$ is left hand. 
after acidification of the serum and addition of hexobarbitone as internal standard, PEMA was extracted in $8 \mathrm{ml}$ of chloroform. After evaporation of the solvent, the final residuum was dissolved in $50 \mu \mathrm{l}$ of chloroform and 1-2 $\mu$ l were injected into the gas-chromatograph fitted with a glass column (159 $\mathrm{cm} \times 3 \mathrm{~mm}$ ID), packed with GP2\% SP-2510-DA on 100/120 mesh Supelcoport (Supelchem Inc, Bellefonte). Chromatograph conditions were as follows: oven temperature $215^{\circ} \mathrm{C}$, detector and injection part $250^{\circ} \mathrm{C}$. Nitrogen was used as the carrier gas.

\section{Results}

The results were subjected to a three factor repeated measures analysis of variance, with week, drug and hand (left and right separately) as the factors. Computer analysis was performed using BMDP 2V version 1977 on the University of London CDC 660 Computer. No significant difference between the effect of PEMA and placebo was found in any of the measures (fig). If anything, there was a trend towards tremor magnitude being greater on PEMA treatment. There was no significant difference in the magnitude of tremor between the first and second week of PEMA treatment. No change of dominant peak frequency was observed during PEMA medication.

Serum levels of PEMA on a daily dose of $400 \mathrm{mg}$ ranged between $11-27 \mu \mathrm{g} / \mathrm{ml}$ and on $800 \mathrm{mg}$ daily between $16-48 \cdot 5 \mu \mathrm{g} / \mathrm{ml}$. The drug was free of sideeffects. One patient developed a transient mild pruritic erythematous eruption on his legs during the first week of treatment with PEMA which resolved without discontinuing the drug.

\section{Discussion}

The results of this study do not support the suggestion of O'Brien $e t a l^{2}$ that the efficacy of primidone in suppressing essential tremor is mainly related to an effect of PEMA because the compound had no discernible effect at a dose which resulted in a steady state serum level that would be expected to be produced by primidone $1500 \mathrm{mg}$ when given on a daily basis. Unfortunately O'Brien et $a l^{2}$ did not state the mean dosage of primidone that resulted in long-term improvement of tremor in their patients. However, it is reasonable to assume that it was not higher than that which would produce the steady state serum levels of PEMA achieved in our patients. Assuming that the therapeutic role of primidone in essential tremor is confirmed with controlled trials, our results suggest that its reported effectiveness is unlikely to be mediated by PEMA. The absence of adverse reactions suggest that the high incidence of intolerance to primidone reported in patients with essential tremor is unrelated to PEMA.

We thank the physicians at the National Hospital, Queen Square for allowing us to study patients under their care, the pharmacy staff at the National Hospital for their assistance, and Dr Helmut Shafer, Desitin-Werk, Hamberg for supplying the PEMA.

\section{References}

${ }^{1}$ Sorensen PS, Paulson OB, Steiness E, Jansen EC. Essential tremor treated with propranolol: lack of correlation tetween clinical effect and plasma propranolol levels. Ann Neurol 1981 ;9:53-7.

${ }^{2}$ O'Brien MD, Upton AR, Toseland PA. Benign familial tremor treated with primidone. Br Med J $1981 ; 282$ : 178-80.

${ }^{3}$ Gallagher BB, Baumel IP. Primidone. Biotransformation. In: Woodbury DM, Penry JK, Schmidt RP, eds. Antiepileptic Drugs. New York: Raven Press, 1972: 361-6. 